\title{
Auditing wildlife
}

\author{
B.K. REILLY and Y. REILLY
}

Reilly B.K. and Y. Reilly. 2003. Auditing wildlife. Koedoe 46(2): 97-102. Pretoria. ISSN 0075-6458.

\begin{abstract}
Accountants and auditors are increasingly confronted with the problem of auditing wildlife populations on game ranches as their clients' asset base expands into this industry. This paper aims to provide guidelines on these actions based on case study data and research in the field of wildlife monitoring. Parties entering into dispute on numbers of animals on a property often resort to their auditors for advice. This paper tracks a method of deciding on whether or not to audit the population based on wildlife value and an initial sample count. This will act as a guideline for the accounting profession when confronted by this problem.
\end{abstract}

Keywords: game counting, game ranches, decision support, operational auditing, helicopter counts.

B.K.Reilly $\triangle$, Department of Nature Conservation, Technikon Pretoria, Private Bag X680, Pretoria, 0001, South Africa; Y. Reilly, Department of Auditing, University of South Africa, P.O.Box 392, Pretoria, 0001 Republic of South Africa.

\section{Introduction}

The current number of game ranches in South Africa is estimated at 8000 (Eloff 2000). Business people who are in part time participants in wildlife own a significant number of these or nature based undertakings. Many of these operations do not have ecological management plans with clearly defined goals and the necessary monitoring actions in place to track their progress. From time to time, on sale of property, expansion, and consolidation or for ad hoc management, owners and their appointed managers resort to once-off game counts. Even more disturbing is the fact that many disreputable operators in the wildlife industry are only too willing to oblige and provide poor data resulting in poor management and strategic decisionmaking. The position is often exacerbated by poor advice from neighbours, relatives and government extension officers, both from conservation and agricultural agencies.

\section{Internal auditing}

All of the above accepted scientific/biological definitions that are essentially within the gambit of what is known as an operational audit. The operational audit is used to judge the quality of operations and make operational improvements in any undertaking (Reider 1994). Because of today's multifaceted and multi-disciplined economic environment, management began to place increasing emphasis on evaluation of the organization's operations with regards to economy, efficiency, effectiveness and impact on the environment. Operational auditing can thus be seen as a service to management as well as improving organizational performance because it involves a systematic review of an entities activities in relation to specified objectives. Performance appraisal involves a comparison of the way in which an entity performs its activities with:

- objectives established by management or any other party asked to do so;

- other appropriate measurement criteria.

\section{Operational auditing}

As a subset of internal auditing, operational auditing reviews undertakings' activities for efficiency and effectiveness (Table 1) and 
Table 1

The relationship between economy, efficiency and effectiveness

\begin{tabular}{ccc}
\hline Input & Activity & Output \\
\hline Economy & Efficiency & Effectiveness \\
Resources & Objectives \\
Doing things right & Doing the right thing \\
\hline
\end{tabular}

may evaluate any type of activity at any level within the organization. The overall objective is maximizing organizational welfare.

Efficiency may be viewed in this definition as an input measure that relates to cost control and is concerned with the performance of recurring functions at a minimum of cost to the undertaking.

Effectiveness is output orientated; it is viewed as a measure of productivity in utilizing the undertaking's resources and in terms of long term profitability.

One might also view this approach as riskbased operational auditing because of its focusing on helping management to improve the way the undertakings activities are performed.

Performance objectives are very important - if they are non-existent, direction, measurement, evaluation and management of performance cannot be achieved. These objectives provide direction as to what management is trying to achieve, a means of measuring the level of achievement as well as benchmarks against which performance can be evaluated.

This performance evaluation provides the trigger to begin actions to correct performance problems or to improving performance by raising standards. According to Reider (1994) operational auditing has many benefits and depending on its scope it can be of significant benefit to management in some or all of the following ways:

- identifying problem areas, related causes and alternatives for improvement;

- locating opportunities for eliminating waste and inefficiency thence cost reduction;

- locating opportunities to increase revenues-improvement of income;

- identifying undefined organizational goals, objectives, policies and procedures;

- identifying criteria for measuring the achievement of organizational goals and objectives;

- recommending improvement in policies, procedure and organizational structure;

- providing checks on performance by individuals and organizational units;

- reviewing compliance with legal requirements and organizational goals objectives and procedures;

- testing for existence of unauthorized fraudulent or otherwise irregular acts;

- assessing management information and central systems;

- identifying possible trouble spots in future operations;

- providing an additional channel for communication between operating levels and top management;

- providing an independent objective evaluation of operations.

What, you may wonder does this have to do with gamecounting? Currently, monitoring of wildlife populations is central to decision making surrounding a resource that provides the backbone of the ecotourism industry. Where wildlife population monitoring still takes place, budgets are shrinking and managers responsible are failing to meet all the requirements of monitoring, biological, statistical and financial. There is a growing perception within the financial management component of organizations that valuable wildlife assets need to be better accounted for. Wildlife on State land is not being adequately accounted for and an operational audit approach may be an avenue for adequate accounting under internal audit responsibility instead of that of the conservation biologist. Internal audit components of Government may be the area of responsibility required to adequately fund and con- 
trol wildlife resources. The time of external operational audit of Government conservation agencies and statutory bodies may have arrived with regard to the wildlife assets of which they are custodians. This in the light of increasing risk to wildlife populations from various quarters.

An underlying principle of auditing is, however, that sampling procedures answer to rigorous statistical requirements in particular error probabilities (Reider 1994). Authors in wildlife management concur that estimates of precision are essential outputs of gamecounts. The relationship between operational auditing and wildlife management in statistical terms is laid out in Table 2.

Collinson (1985) observed that there were limitations with helicopter-based surveys, which form the backbone of gamecounting in Southern Africa. The results of Reilly (2000) directly support Collinson's (1985) contention that the method has severe limitations where repeatable estimates over time are required unless more than four counts are contemplated. Reilly (2000) draws the following conclusions on helicopter total counts in his study:

- the method is incapable of consistently detecting small population $(10-20 \%)$ changes at acceptable power and significance under moderate replication (3-3) or high significance (talpha.1);

- the precision and power attained in this limited study is entirely site specific. It is difficult to make any general statements about either;

- the assumption of constant variance from $t_{1}$ to $t_{2}$ cannot be validated;

- operating time for the method should be limited with operations over 2,5 hours being corrected for decline in observations over time;

- cognizance should be taken of the differing observation profiles of observers in the initial choice of observers for gamecounts.

Failures of techniques, be they helicopter, fixed-wing or ground-based methods, com- bined with declining financial resources have forced monitoring programmes back to a point of serious review by both management and biologists. The increasing value of wildlife, on the other hand, combined with its pivotal role in the hunting and ecotourism industry, necessitates a new approach to justifying costing and implementing such programmes. Clearly the value of wildlife has to enter into determination of monitoring efficiency, effectiveness and budgeted cost. The proposed audit hypothesis model forms the basis of decision making in whether or not the count should take place. This is based on a sample which can be extracted from previous counts.

\section{The operational audit route}

\section{Statistical sampling}

The internal auditor can assist in two ways, viz., determination of monetary value of the unit to be audited, and consideration of the statistical sampling technique. Normally wildlife managers select the appropriate counting technique for monitoring wildlife and very often ignore the statistical considerations. Biologists generally take a different view of statistical sampling to that of managers. Reilly (2000) and Thompson et al. (1998) point to the fact that wildlife managers and some biologists ignore the rules of inference in determining large ungulate numbers. It appears that the audit profession concurs and the internal auditors have found the use of certain statistical sampling techniques advantageous in certain instances. The use of statistical sampling does not reduce the use of judgement by the auditor but provides certain statistical measurements as to the results of audit tests, which measurements may not otherwise be available.

When an auditor is faced with a situation requiring the projection of a total quantity or total Rand value, based on a mean of a sample, accounting estimation is the appropriate tool to use (Guy et al. 1998).

By using estimation sampling, a projection can be made of the estimated population value that becomes the booked amount. The estimated population value plus and minus calculated precision is expected to contain the true but unknown value at a defined reliability level. 
Table 2

Relationship between statistical terms, operational auditing and wildlife monitoring

\begin{tabular}{llll}
\hline & Statistical terms & Audit terms & Gamecount \\
\hline Risk of incorrect rejection & Alpha risk & Audit efficiency & Significance/risk of Type I error \\
Risk of incorrect acceptance & Beta risk & Audit effectiveness & 1 - Power/risk of Type II error \\
\hline
\end{tabular}

\section{The audit hypothesis model}

In statistics the risk of incorrect rejection is called the alpha risk and the risk of incorrect acceptance is called the beta risk. The relationship between audit terms and statistical terms are as follows:

Alpha risk is the chance that the statistical evidence might fail to support a materially correct book value. This type of error usually results in testing additional sample items. Decreasing or increasing reliability controls this risk. For reliability in auditing read precision in wildlife monitoring. In wildlife management terms a decision based on population change shown in a sample that did not occur in reality.

Beta risk is the probability that the statistical evidence might support a lack of material. Beta risk is controlled by adjusting the ratio of precision a to materiality. Again in wildlife terms increasing precision reduces this risk and in management terms this is a scenario of no change shown by the sample when in reality change has occurred.

\section{Audit hypotheses testing}

When the auditor's primary concern is controlling beta risk, effectiveness - (output orientated) thus utilizing the resources in terms of long-run profitability - as discussed under operational auditing, he will use this method: In the previous method discussed beta risk was not considered because we were not trying to decide if a book value was materially misstated.

If an auditor rejects the recorded inventory value the client will generally insist on an increase in sample size or a search for additional evidence to show that the inventory balance is misstated.

In this method the audit hypothesis model differs from the previous method as follows: the calculated desired beta risk must be calculated taking into consideration audit risk, internal control and other audit procedures results. Once precision is determined, the substantive test sample size is then calculated.
After the sample items selected are audited, the auditor ascertains whether the statistical evidence supports material correctness of the client's book value.

The audit hypothesis model (AHM) is ideally suited to wildlife management undertakings. It consists of a 22 step approach, beginning with assessment of internal control and ending with an accept or reject decision as to material misstatement of a balance - in this case the number of animals, grasses or trees, i.e., the wildlife asset.

The model will be explained by way of an example that commences with Table 3 .

From the operational audit standpoint, this reserve has a stock of 1289 items of varying value. A counting (audit) programme is in place. Based on (1) tests of control of the inventory count (2) observation that the gamecount instructions are followed, and (3) the evaluation of the competence of personnel undertaking the count, it is decided that the control risk (CR) is no more than $20 \%$.

Management decides that the inventory valuation of R 9755805 is acceptable if actual inventory is within 5\% (95\% confident) of this value. The statistical test will be based on recounting, repricing and extending each item in the sample (part of a count). Other audit procedures (AP) consist of inventory turnover calculations (population dynamics), comparison to previous years and cutoff tests to ensure that purchases and sales are reflected in the inventory for the period. At a guess these procedures are estimated at $80 \%$ risk.

Substantive test planning now begins with the calculation of sample size using the following equation:

$$
n^{\prime}=\left(U_{R} \cdot S D \cdot N / A\right)^{2}
$$

$U_{R}$ is already defined as 1,96 ( $95 \%$ confidence), $S D$ is calculated from the value of the sample, $N$ is the 1289 items and $A$ needs to be calculated.

Firstly beta (Type II error) risk is calculated based on audit risk of 5\% (95\% confidence) assessed control 
Table 3

Mean number of animals counted from 4 replicate counts on Loskop Dam Nature Reserve (1991), mean Rand value (Eloff, 2000), total value and values from a random sample count of 1 hour

\begin{tabular}{lccccc}
\hline Species & Mean No. & Mean value (2000) & Total value & No in sample & Sample value \\
\hline Kudu & 259 & R2 105.00 & R544 142.50 & 3 & R6 315.00 \\
Zebra & 239 & R2 640.00 & R630 300.00 & 8 & R21 120.00 \\
Wildebeest & 186 & R2 226.00 & R414 036.00 & 26 & R57 876.00 \\
Impala & 317 & R596.00 & R188 783.00 & 52 & R30 992.00 \\
Warthog & 39 & R567.00 & R21 971.25 & 11 & R6 237.00 \\
Sable & 41 & R53 580.00 & R2 210 175.00 & R0.00 \\
White rhino & 30 & R176 801.00 & R5 304 030.00 & 2 & R353 602.00 \\
Mountain reedbuck & 156 & R993.00 & R154 659.75 & 18 & R0.00 \\
Giraffe & 23 & R12 509.00 & R287 707.00 & & R494 016 \\
\hline Total & 1289 & R252 017 & R9 755 805 & 120 & R113 508 \\
\hline Standard deviation $(S D)$ & R58 360 & R1 836.34 & & & \\
Standard error $(S E)$ & & & & & \\
\hline
\end{tabular}

risk $(C R)$ of $20 \%$ and other procedural risk $(A P)$ of $80 \%$, beta is:

$$
\operatorname{beta}(\text { planned })=(0.05 / 0.20 \times 0.80)=0.3125
$$

The beta risk coefficient is $0,5-0,3125$ which is 0,1875 . Using a normal area curve table we see that this corresponds to a beta risk coefficient $\left(Z_{\text {beta }}\right)$ of 0,49 . Beta is controlled by varying the precision of $A$ in relation to tolerable misstatement (TM) (Rand value $\pm 5 \%$ ).

$$
A=T M .\left(U_{R} / U_{R}+Z_{\text {beta }}\right)=R 390232
$$

This is acceptable precision as it falls inside the Rand value $\pm 5 \%$.

The sample size calculation is now:

$$
n^{\prime}=\left(U_{R} \cdot S D \cdot N / A\right)^{2}=4679
$$

This is the sample size with replacement, the samples size without replacement is:

$$
n^{\prime}=(4679 / 1+(4679 / 1289)=1011
$$

At this point if the sample appears representative the sample is audited. $A^{\prime}$ is now calculated for which the $S D$ of the sample (Table 3) and the sample is required:

$$
A^{\prime}=\left(U_{R} \cdot S E \cdot N \sqrt{1-n / N)}=R 2158694\right.
$$

If $A^{\prime}$ is not equal to $A$ then $A^{\prime \prime}$ must be calculated:

$$
A^{\prime \prime}=\left(A^{\prime}+T M\left(1-A^{\prime} / A\right)=R 47434\right.
$$

Estimated audited value (EAV) is the mean of the sample value times $N$ or R5 306 555.20. A decision interval of book value (R9 755805$) \pm A^{\prime \prime}$ or R9 $755805 \pm$ R47 434. Clearly the EAV falls outside this decision interval, therefore the statistical evidence does not support material correctness.

The implications are that the entire stock should be audited.

The effectiveness of a count or audit can be measured using statistical power as an index. Reilly \& Haskins (1999) have amply demonstrated this for counts on Suikerbosrand Nature Reserve. The issue of efficiency, viz., the ratio of output to input can also be illustrated using statistical power. The relationship between power per number of replicates calculated against the cost of those replicates allows decision making on optimizing in this area. Table 4 shows this relationship. It is evident from Table 4 that as replicates increase efficiency improves - it is cheaper to count more often.

Finally, how much to spend. The audit profession has no fixed guidelines in this regard, relying on the objective evaluation of the auditor. With what we have seen so far, the auditor will definitely decide on a full audit. In the absence of fixed formulae, the authors propose that $1 \%$ of the value of the stock be allocated to the audit. 
Table 4

Cost per percent statistical power (1-beta) to show $15 \%$ population change at $10 \%$ significance for populations (stock) on Loskop Dam Nature Reserve

(power analysis based on actual counted replicates) using helicopter based surveys at current prices

\begin{tabular}{lccccccc}
\hline & \multicolumn{7}{c}{ Species } \\
kudu & zebra & wildebeest & impala & warthog & sable & warthog & Mt reedbuck \\
\hline R832.76 & R1 097.73 & R1 271.05 & R1 420.59 & R1 610.00 & R1 271.05 & R1 150.00 & R3 450.00 \\
R402.50 & R589.02 & R690.00 & R805.00 & R1 006.25 & R710.29 & R619.23 & R2 683.33 \\
R305.70 & R431.25 & R525.00 & R603.75 & R754.69 & R525.00 & R464.42 & R2 415.00 \\
R473.53 & R710.29 & R862.50 & R928.85 & R1 150.00 & R832.76 & R731.82 & R3 018.75 \\
R271.35 & R355.15 & R423.68 & R473.53 & R603.75 & R409.32 & R371.54 & R2 195.45 \\
R383.33 & R575.00 & R690.00 & R779.03 & R966.00 & R670.83 & R603.75 & R2 683.33 \\
R280.81 & R383.33 & R455.66 & R503.13 & R652.70 & R439.09 & R395.90 & R2 415.00 \\
R256.91 & R317.76 & R377.34 & R416.38 & R525.00 & R360.45 & R330.82 & R2 012.50 \\
R248.97 & R290.96 & R330.82 & R365.91 & R464.42 & R322.00 & R298.15 & R1 857.69 \\
\hline
\end{tabular}

\section{Summary and conclusions}

In this paper we have seen that it is possible to provide concrete decision support in terms of the key questions that surround the ubiquitous gamecount. These questions are becoming more relevant as conservation agencies, in particular, struggle for funding.

Considering the custodianship entrusted to these organizations and the monetary value of the wildlife coupled with the fact that the biologists have to perpetually seek funding to undertake the gamecounts, a shift of responsibility in this regard to an internal audit component is indicated. With a random sample from a previous count, a known book value of each ungulate, published mean power values and a little bit of borrowed technology a desktop exercise provides answers to all the posed questions. The time has come for the competent, realistically funded audit of wildlife with commensurate audit responsibilities while the biologists get on with the field techniques.

\section{References}

Collinson, R.H.F. 1985. Selecting Wildlife Census Techniques. Monograph 6, Institute of Natural Resources, University of Natal, Pietermaritzburg.

Eloff, T. 2000. Gemiddelde wildveilingpryse vir Suid Afrika, 2000. Unpublished report, University of Potchefstroom.

GoldSMith, F.B. 1991. Monitoring for conservation and ecology. London: Chapman.

GuY, D.M., D.R. CARMiChaEl \& O.R. WhitTington. 1998. Audit sampling. An Introduction. New York. John Wiley.

REIDER, H.R. 1994. The complete guide to operational auditing. New York: John Wiley.

ReILlY, B.K. \& C.I. Haskins. 1999. Comparative efficiency of two game counting techniques as applied to Suikerbosrand Nature Reserve. South African Journal of Wildlife Research 29(3): 89 97.

REILLY, B.K. 2000. The statistics of helicopter total counts of large ungulates in sourish mixed bushveld, northwest arid bushveld and mopane veld, Republic of South Africa. Unpublished thesis, University of Stellenbosch.

Thompson, W.L., G.C. White \& C. Gowan. 1998. Monitoring vertebrate populations. San Diego: Academic Press. 